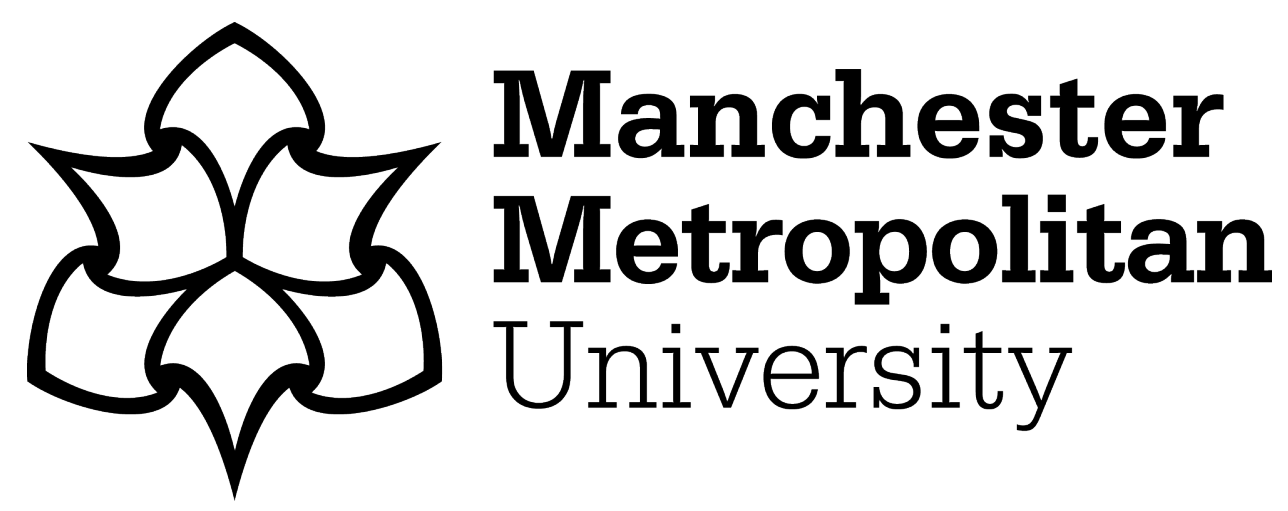

Liu, Y, Liskiewicz, TW ORCID logoORCID: https://orcid.org/0000-0002-0866$814 X$ and Beake, BD (2019) Dynamic changes of mechanical properties induced by friction in the Archard wear model. Wear, 428-42. pp. 366-375. ISSN 0043-1648

Downloaded from: https://e-space.mmu.ac.uk/623037/

Version: Accepted Version

Publisher: Elsevier

DOI: https://doi.org/10.1016/j.wear.2019.04.004

Usage rights: Creative Commons: Attribution-Noncommercial-No Derivative Works 4.0

Please cite the published version 


\title{
Dynamic changes of mechanical properties induced by friction in the
}

\section{Archard wear model}

\author{
Yanfei Liu ${ }^{1,2^{*}}$, Tomasz W. Liskiewicz ${ }^{1 *}$, Ben D. Beake ${ }^{3}$
}

${ }^{1}$ School of Mechanical Engineering, University of Leeds, Woodhouse Lane, Leeds

$$
\text { LS2 9JT, UK }
$$

${ }^{2}$ State Key Laboratory of Tribology, Tsinghua University, Beijing 100084, China

${ }^{3}$ Micro Materials Ltd., Willow House, Yale Business Village, Ellice Way,

Wrexham LL13 7YL, UK

${ }^{*}$ Corresponding author.

E-mail address:

yanfeiliu@mail.tsinghua.edu.cn (Y. Liu)

t.liskiewicz@leeds.ac.uk (T.W. Liskiewicz) 


\begin{abstract}
Fretting is small-amplitude, oscillatory motion between two bodies leading to surface damage. During the fretting process, a tribologically transformed structure (TTS) which has different mechanical properties and microstructure than the starting material is formed on the surface. The commonly-used Archard wear equation relating wear volume to the hardness of the worn material does not account for changes in mechanical properties induced by friction in fretting. To investigate that effect, ball-on-plane fretting tests were conducted on three engineering materials (type 316 stainless steel, pure copper, and titanium alloy Ti-6Al-4V) against an alumina ball to generate TTS layers. The evolution of mechanical properties and microstructures of TTS layers were investigated using nanoindentation and focused ion beam-scanning electron microscope (FIB-SEM). Wear volumes after different fretting cycles were measured with a white light interference microscope. Results show that the mechanical properties of TTS layers evolve differently on different materials during the fretting process. Microstructures of TTS layers also vary from one material to the other. A modified wear model that accounts for friction-induced dynamic changes in mechanical properties is proposed. In these tests the modified model was able to predict the wear volume of 316 steel and pure copper more accurately than the classical Archard model, but it was less successful in predicting wear on Ti6Al4V where there is added complexity from changing microstructure, oxidation, porosity and cracking.
\end{abstract}

Keywords: fretting, tribologically transformed structure (TTS), nanoindentation, wear prediction, Archard model 


\section{Introduction}

Fretting is a small amplitude oscillatory motion between two bodies leading to surface damage. The nature of damage depends in fretting on the amplitude and loading conditions [1]. Fretting with small amplitude and high load usually leads to fretting fatigue, while large-amplitude and low-load fretting typically leads to wear [2]. In fretting fatigue scenario, cracks are initiated at the fretting interface, which then propagate into the substrate without much loss of material volume. Under fretting wear, the interface firstly goes through plastic deformation followed by wear debris formation and detachment from the bulk material. In metallic materials, fretting wear process is usually accelerated by oxidation, resulting in synergy between the mechanical and chemical processes [3-7].

Accurate wear prediction remains a major challenge, however the classical Archard model is still probably the most commonly used way of assessing wear performance of materials $[8,9]$. In this model, wear volume is a function of hardness of the material, sliding distance and applied normal load. Over the years researchers proposed other ways of predicting wear, e.g. Fouvry et al. presented a quantitative approach to characterize wear specifically in fretting regime [10]. In this approach, fretting damage is related to the amount of energy dissipated during fretting, and the formation and ejection of wear debris can be estimated as well. Another approach was proposed taking into account the elastic strain and toughness of materials, and hardness to elastic modulus ratio $(H / E)$ was used to estimate wear behaviour $[11,12]$. More recently, a model was proposed where wear behaviour is related to the yield strength of 
material. It has been found that the yield strength to elastic modulus ratio has a positive correlation with wear performance [13].

During friction, the crystallographic structure of the TTS layer within the tribological contact is subjected to dynamic changes, which was investigated by both experiments $[14,15]$ and molecular dynamics simulation [16]. The crystallographic structure changing is a complex process. Non-uniform partial dislocation model for flow stress $[17,18]$ and unified mechanistic model for size-dependent deformation [19] were generalized to investigate the plastic deformation process. Crystal size has influence on the wear performance of alloys. Nanocrystalline alloys have better wear performance comparing to microcrystalline alloys, which is consistent with their higher hardness [20]. Researchers also found that the grain size have influence on the friction behaviour $[20,21]$. Low and high friction are related to the nano-scale mechanisms of grain boundary and dislocation-mediated plasticity [21]. Studies of the third-body layers have shown that metallic materials subjected to friction, tend to generate a specific transformed layer within the contact area [22]. This layer, called Tribologically Transformed Structure (TTS) corresponds to the intermediate stage between a material of the first-body and debris of the third-body. Even though the existence of the TTS layer has been well proven, the dynamics of its formation and transformation mechanisms are still not clear.

Zhou et al. investigated formation of the TTS layer during fretting wear under different conditions, including slip amplitude, normal load, frequency and number of cycles [23]. It was found that the TTS nucleated relatively quickly, and after 100 cycles 
a TTS layer of $100 \mu \mathrm{m}$ thickness was observed. In order to analyse the evolution of the TTS layer quantitatively, the dissipated energy approach and fretting maps method were proposed $[24,25]$. It was also found that the increase of hardness during fretting can be related to the strain-hardening in metals [25]. Strain-hardening occurs during plastic deformation, which is induced by the dislocation and twinning of metal crystals $[26,27]$. The strain-hardening process is related to the stacking fault energy which varies for different materials [28], which can result in different TTS properties [24]. The through-thickness mechanical properties of the TTS layer have also been investigated by nanoindentation of cross-sections [29].

Although the existence of the TTS layer is accepted and its performance has been widely investigated, the mechanism of its formation is still unclear. The relationship between evolution of the TTS layer and wear behaviour has not been fully understood, and there is no reliable wear model taking into account the dynamic changes of mechanical properties induced by friction in fretting. Further understanding of this process will have significant consequences for the reliability of wear models and overall prediction of the tribological performance of components.

\section{Experimental}

\subsection{Materials}

Three commonly used engineering materials were selected for this study: 316 stainless steel, pure copper, and Ti6Al4V titanium alloy. All specimens were cut out of the bars to the same sample height of $5 \mathrm{~mm}$. All disc specimens were mounted in resin, 
grounded with sandpapers and polished with 5, 3 and $0.25 \mu \mathrm{m}$ diamond suspension. After polishing, all specimens were taken out from the resin mount, cleaned with deionized water and acetone and dried for further use. Alumina is commonly used as bearing and sealing parts owing to its high hardness, anti-corrosion and wear resistance performance. Alumina is also chemically inert material which helped our approach which was focused on mechanical properties. Hence, alumina balls with $16 \mathrm{~mm}$ diameter were used in this study as a counter-body.

\subsection{Fretting setup}

A ball-on-plane electro-dynamic shaker powered fretting setup designed and built in School of Mechanical Engineering at the University of Leeds was used in this study. Schematic diagram of the fretting setup is presented in Figure 1(a). During fretting tests, flat metallic disc samples were fixed in the static holder while the alumina counterbody ball was fixed onto the shaker. The amplitude, frequency, applied normal load and test duration were set in the fretting setup software. The normal load was applied with a dead weight, which was calibrated prior to the experiment using a load cell. The tangential force during fretting experiment was measured using Kistler piezoelectric force sensor. The workflow diagram of the protocol for the displacement amplitude control is shown in Figure 1(b). At the beginning of the fretting test, an initial tangential force was applied by the shaker, and the displacement was measured with a non-contact laser sensor then compared with the set value. If the displacement was higher than the set value, the tangential force would be decreased in the following fretting cycle. 
Conversely, if the displacement was lower than the set value, the tangential force would be increased in the following fretting cycle. The process was repeated until the set displacement stabilised. All experiments were carried out in a dry contact environment under $10 \mathrm{~N}$ normal load, in ambient laboratory conditions, at $22^{\circ} \mathrm{C}$ and relative humidity in the range $40-55 \% \mathrm{RH}$. The study focussed on the wear trends rather than comparison of individual tests, however selected tests were repeated up to three times giving a test-to-test confidence of max. $5 \%$ variance.

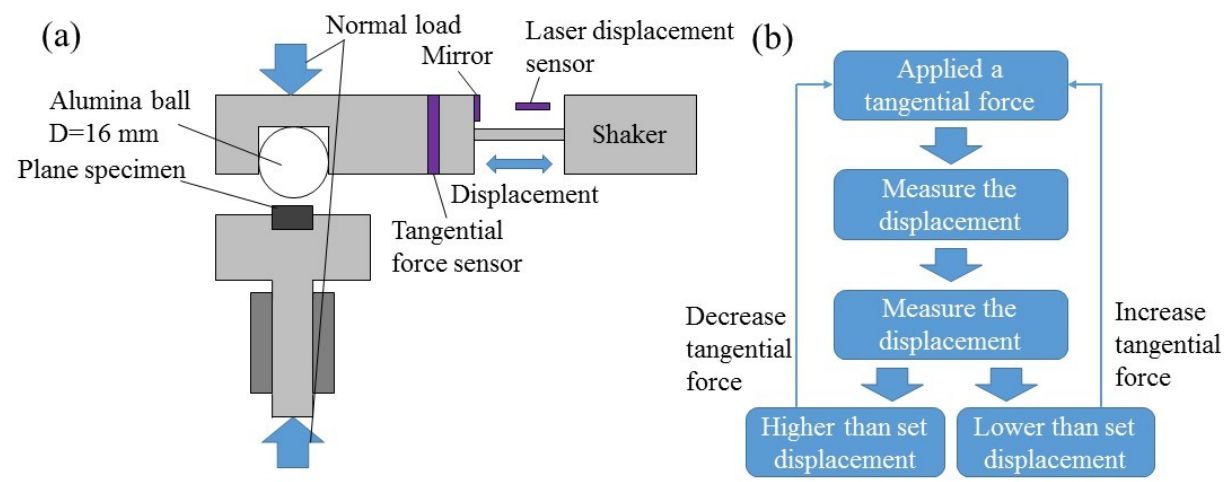

Figure 1. (a) Schematic diagram of the fretting setup, and (b) workflow diagram of the protocol for the displacement amplitude control.

In this study, 10, 50, 100, 200 and 1000 fretting cycle tests were conducted with 1 $\mathrm{Hz}$ frequency to obtain a stable condition to investigate the evolution of TTS layer. 5000, 10000, 20000, 50000 and 100000 fretting cycle tests were conducted with $3 \mathrm{~Hz}$ frequency, in order to investigate the evolution of wear volume. The experiments were performed under $\pm 100 \mu \mathrm{m}$ displacement amplitude resulting in gross-slip fretting regime.

\subsection{Nanoindentation measurements}

Surface hardness of bulk materials and TTS layer within wear scars after different 
fretting cycles were measured using a NanoTest system (Micro Materials Ltd., Wrexham, UK) [30]. For the wear scars with 50-200 fretting cycles, 1x16 indentation lines were generated, traversing the wear scars in order to capture the hardness change induced by fretting (Fig. 2a). For wear scars with 10 and 1000 fretting cycles, an 8x5 indentation matrix was generated to investigate the hardness within the wear scars (Fig. 2b). Distance between the indentation points was set at $25 \mu \mathrm{m}$ to eliminate the influence of the neighbouring indent. The maximum applied load, loading rate and holding time at maximum load before unloading were $50 \mathrm{mN}, 1.5 \mathrm{mN} / \mathrm{s}$ and $5 \mathrm{~s}$, respectively. The Oliver and Pharr method was used to analyse the nanoindentation data [31, 32]. The TTS generation and characterisation experiments performed in this study are shown in Fig. 3 as a flow diagram.
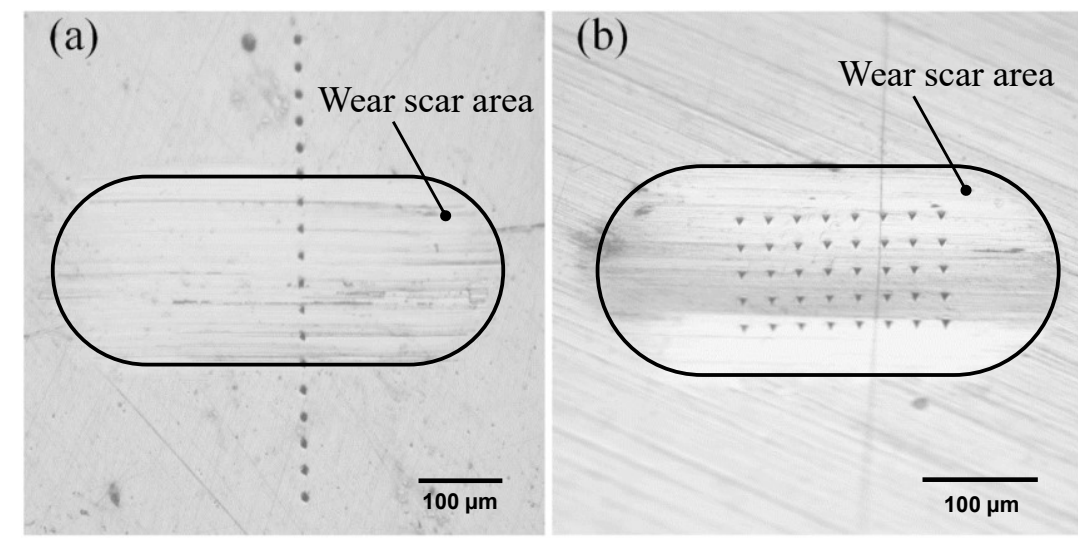

Figure 2. Wear scar on pure copper after 10 fretting cycles; a) $1 \times 16$ indentation line, and b) $8 \times 5$ indentation matrix.

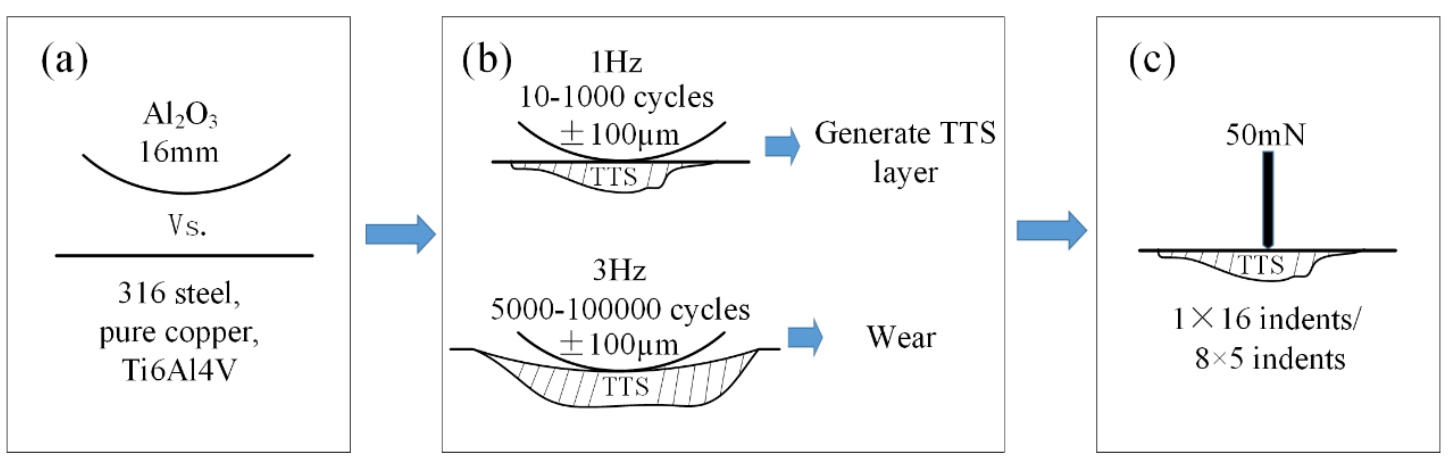


Figure 3. TTS formation and characterisation; (a) materials selection, (b) fretting experiments, and (c) TTS probing by means of nanoindentation.

\subsection{Post-test surface characterisation}

The wear scars on three materials after 1000 fretting cycles were analysed with focused ion beam (FIB) to obtain the cross-sectional images of the TTS layers (Helios G4 CX DualBeam, FEI, USA). The cross-section element distribution was measured with line EDS scanning (Oxford Instruments, UK) to investigate the surface oxidation due to fretting. Wear scars after 5,000-100,000 fretting cycles were characterised with optical 3D profiler (NPFLEX 3D, BRUKER, Germany) in order to investigate the surface morphology, roughness and wear volume.

\section{Results}

\subsection{Nanoindentation characterisation}

The mechanical performance of bulk materials and TTS layers formed under fretting was investigated with nanoindentation technique. The typical result of $8 \times 5$ indentation matrix experiment within the wear scar area on pure copper after 10 fretting cycles can be seen in Fig. 4. In total, 40 curves can be observed in the figure, with each curve representing one indentation test. The indentation curves indicate variation of mechanical properties of the TTS layer within the wear scar. 


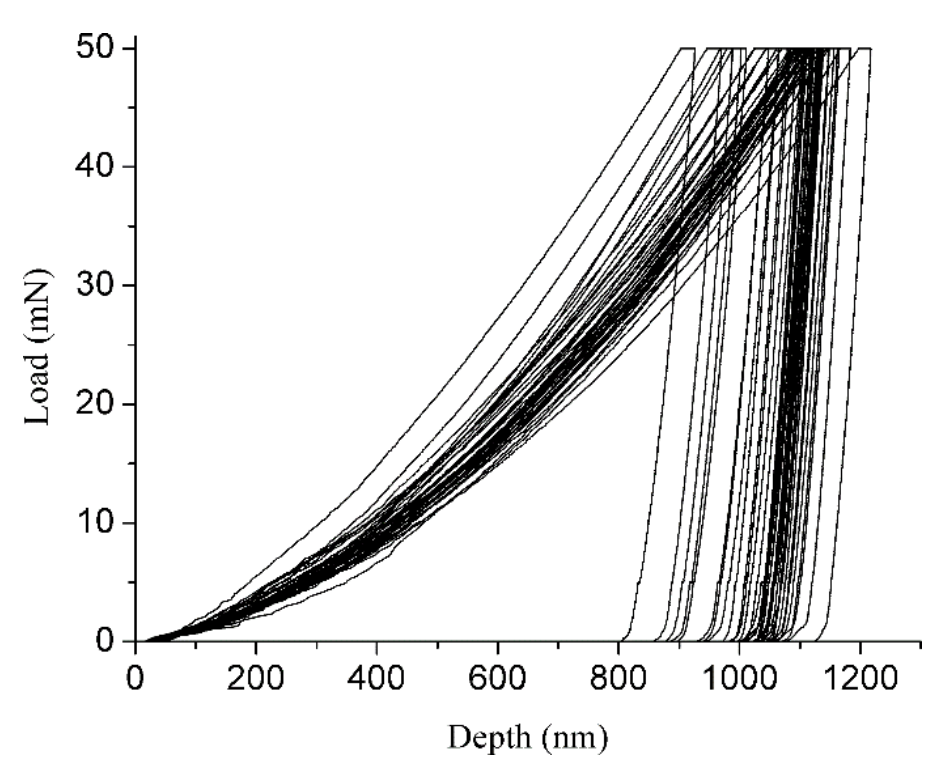

Figure 4. Representative indentation curves of the TTS layer on pure copper sample after 10 fretting cycles.

The hardness of virgin materials and TTS layers with different fretting cycles are shown in Fig. 5. For wear scars with 10 and 1000 fretting cycles, the average hardness results obtained from the $8 \times 5$ indentation matrices were used as a measure of the surface hardness of TTS layer. For the wear scars with 50-200 fretting cycles, 1x16 indentation lines were generated, where some of the indentation points were located within the wear scars (see Figure 2a). The average hardness results obtained with the indentation points in wear scars were used to represent the hardness of TTS layer. The amount of indentation points within wear scars varies from 6-12 because that the dimension of wear scars is influenced by materials performance and test durations. The error bars represent for standard deviations, which were calculated as follows:

$$
S=\sqrt{\frac{\sum_{i=1}^{n}\left(s_{i}-\bar{s}\right)^{2}}{n}}
$$

where $s_{i}$ is a single result and $\bar{s}$ is the mean value of all the results. 
(a)

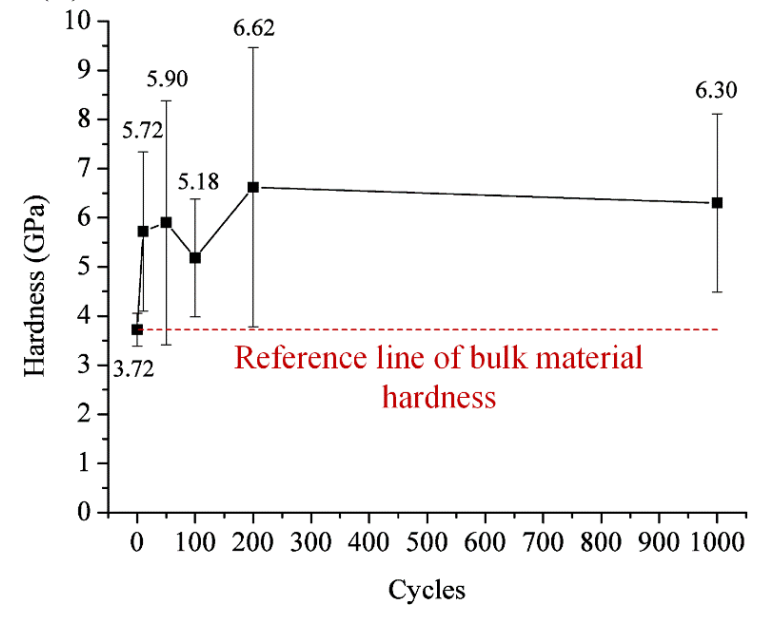

(b)

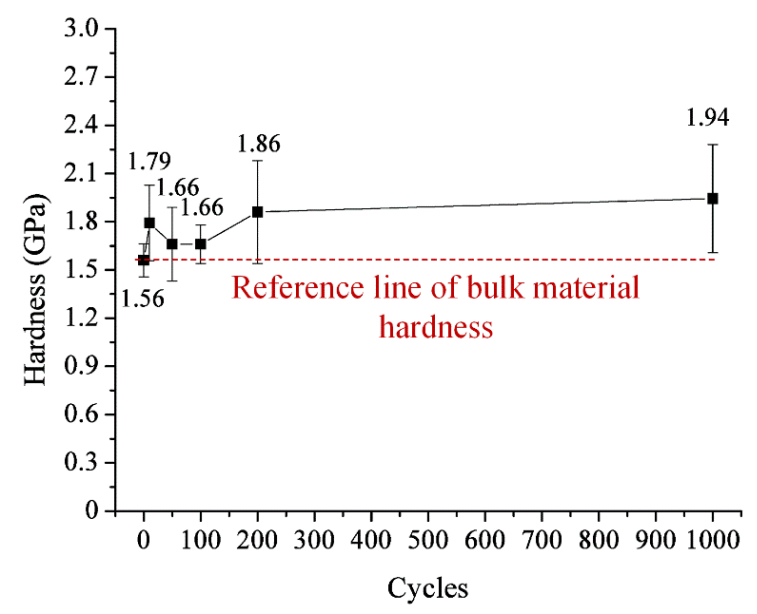

(c)

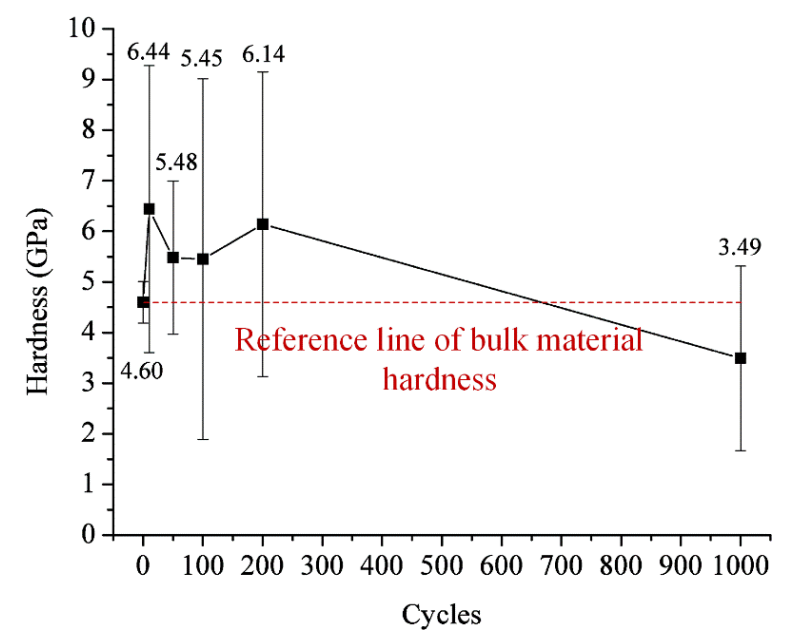

Figure 5. Nanoindentation hardness after 10-1000 fretting cycles; (a) 316 steel, (b) copper and (c) Ti6Al4V. Hardness at zero cycles corresponds to the bulk material hardness. Note different hardness scale for copper sample (b). 
It can be seen that the hardness of TTS layer of different materials follows different trends with increasing fretting cycles. For all materials, significantly enhanced hardness of TTS layer can be observed after 10 fretting cycles. The hardness of virgin 316 steel, pure copper and Ti6Al4V was $3.7 \mathrm{GPa}, 1.6 \mathrm{GPa}$ and 4.6 $\mathrm{GPa}$, respectively. The hardness measured within the wear scars after 10 fretting cycles was 5.7 GPa, 1.8 GPa and 6.4 GPa, respectively. These correspond to increases in hardness of 316 steel, pure copper and Ti6Al4V of $54 \%, 15 \%$ and $40 \%$ respectively in only 10 fretting cycles. The data show that TTS layer is formed during the very early stage of the fretting process, as has been reported by Zhou et al. [23].

The hardness of TTS layers generated on 316 steel and pure copper samples was higher than that of bulk material during the entire 1000 fretting cycle experiment, with hardness of 316 steel increasing more significantly than that of pure copper sample. The hardness of TTS layers on 316 stainless steel and pure copper after 1000 fretting cycles was $6.3 \mathrm{GPa}$ and $1.9 \mathrm{GPa}$, respectively, an increase from 10 fretting cycles $(5.7$ GPa and $1.8 \mathrm{GPa}$ ), but little difference between 200 and 1000 fretting cycles (6.6 GPa and $1.9 \mathrm{GPa})$.

Ti6A14V sample showed a very different performance comparing to the other two materials. It can be seen that the TTS layer after 10-200 fretting cycles showed higher hardness comparing to a virgin material (4.6 GPa), while the TTS layer after 1000 cycles fretting showed lower hardness (3.5 GPa).

The hardness maps generated within the wear scars of three materials after 10 and 1000 fretting cycles are plotted in Fig. 6. The contour plots show the spatial 
variation of hardness within the wear scars corresponding to the error bars presented in Fig. 5.
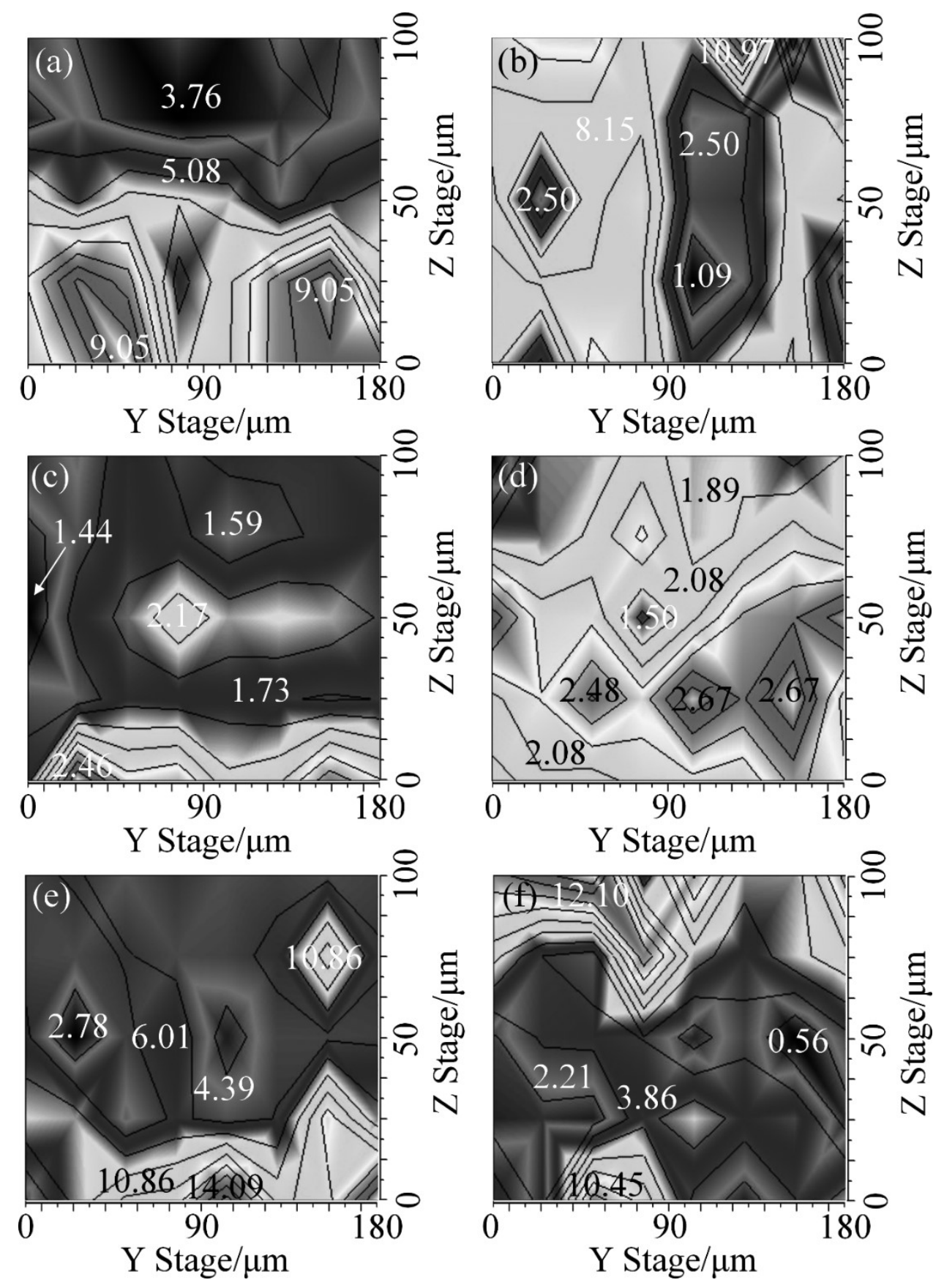

Figure 6. Indentation mapping marked with hardness value (GPa) of different regions.

a-b) Steel with 10, 1000 fretting cycles; c-d) Copper with 10, 1000 fretting cycles; e-f)

Ti6A14V with 10, 1000 fretting cycles 


\subsection{TTS morphology and elemental distribution}

The cross-section morphology and elemental distribution within the TTS layers were investigated using FIB-SEM and EDS. Fig. 7 (a) shows a FIB cross-section of the fretting wear scar on 316 steel sample. Under the protective white layer, a dark layer of approximately $200 \mathrm{~nm}$ can be observed. This can be correlated with a peak of approximately $0.2 \mu \mathrm{m}$ width shown in the oxygen EDS scan in Fig. 7 (b).
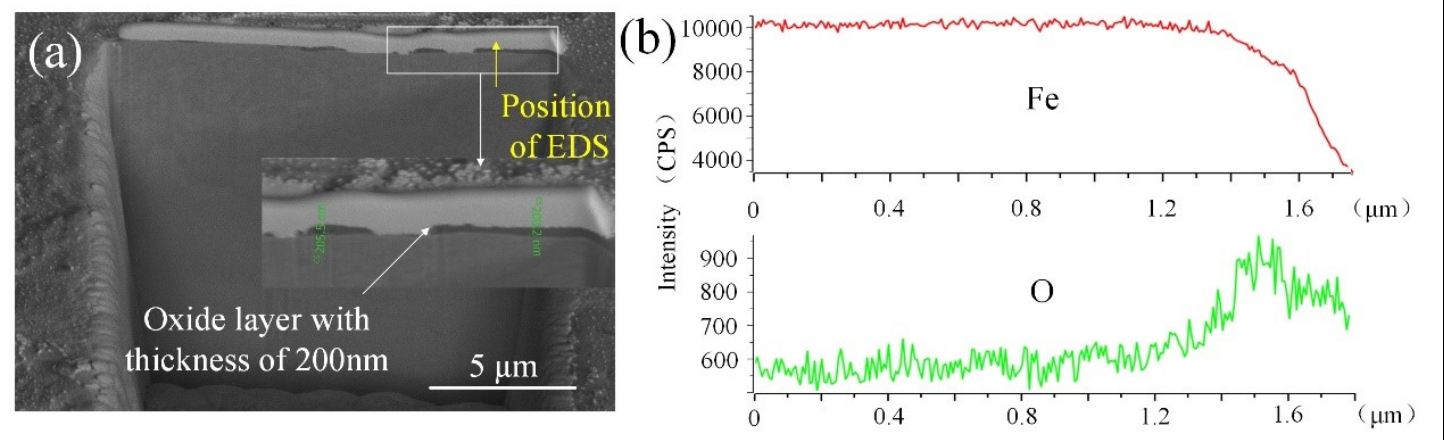

Figure 7. (a) FIB cross-section morphology of the wear scar of 316 stainless steel,

(b) EDS line scans of the wear scar cross-section.

No significant oxidation can be observed within the TTS layer on copper sample. However, refined crystal morphology induced by fretting process can be observed on FIB-SEM cross-section, as shown in Fig 8 (a). A fine grain layer, which has a thickness of approximately $2 \mu \mathrm{m}$ was induced by fretting on the surface of TTS layer, while the virgin material underneath has visibly larger grain size. From EDS scans, it can be observed that surface oxidation of the TTS layer of pure copper was not as 
severe as 316 steel (Fig. 8b).
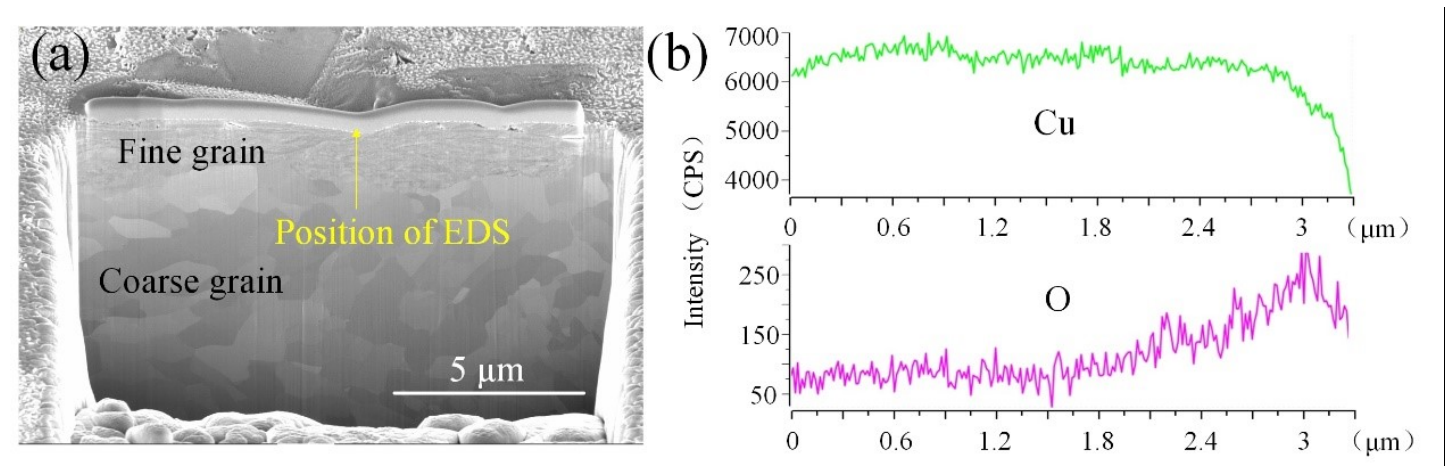

Figure 8. (a) FIB cross-section morphology of the wear scar of pure copper, (b) EDS

line scans of the wear scar cross-section.

Fig. 9 (a) shows that the TTS layer on the Ti6Al4V sample has different morphology to that on the 316 steel and pure copper samples. On Ti6Al4V there is a clear boundary between the crack-free bulk material and a porous TTS layer with approximately $4 \mu \mathrm{m}$ thickness formed during fretting wear process. A thin darker layer was also observed on the TTS layer surface of Ti6Al4V. After etching with FIB, the crystallographic structure of Ti6Al4V can be observed more clearly. Similarly as the pure copper sample, a fine grain layer can be found below the porous layer (Fig. 9b). The EDS scans in Fig. 9 (c) show that the TTS layer surface oxidation of Ti6Al4V after 1000 fretting cycles is more severe than for the other two materials. The TTS layer can be divided into low-oxidised and high-oxidised regions, which correspond to the thin dark layer and the thick porous layer, respectively. 

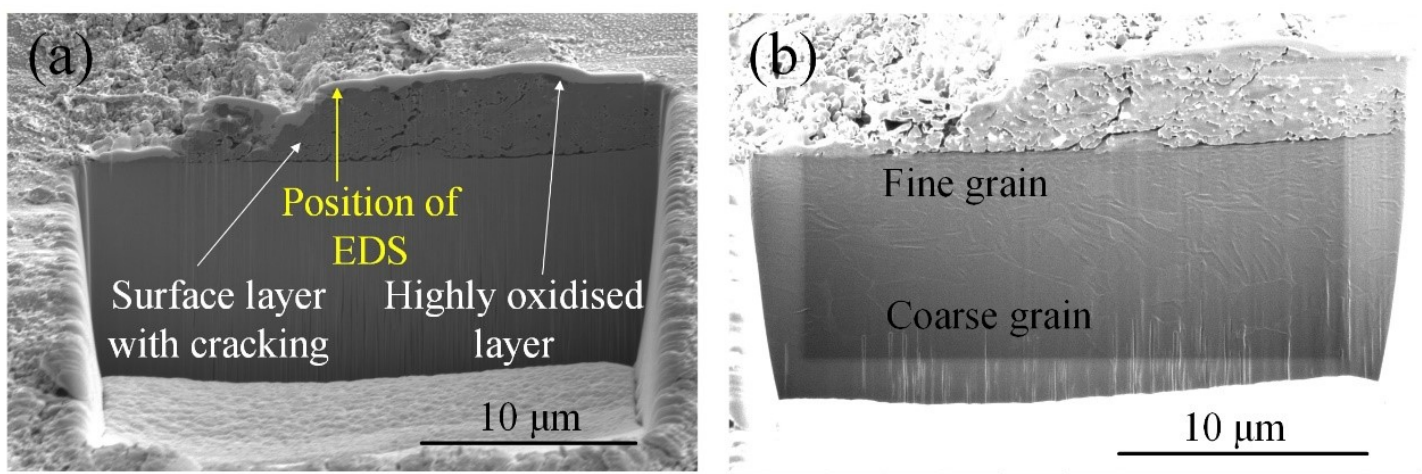

(c)
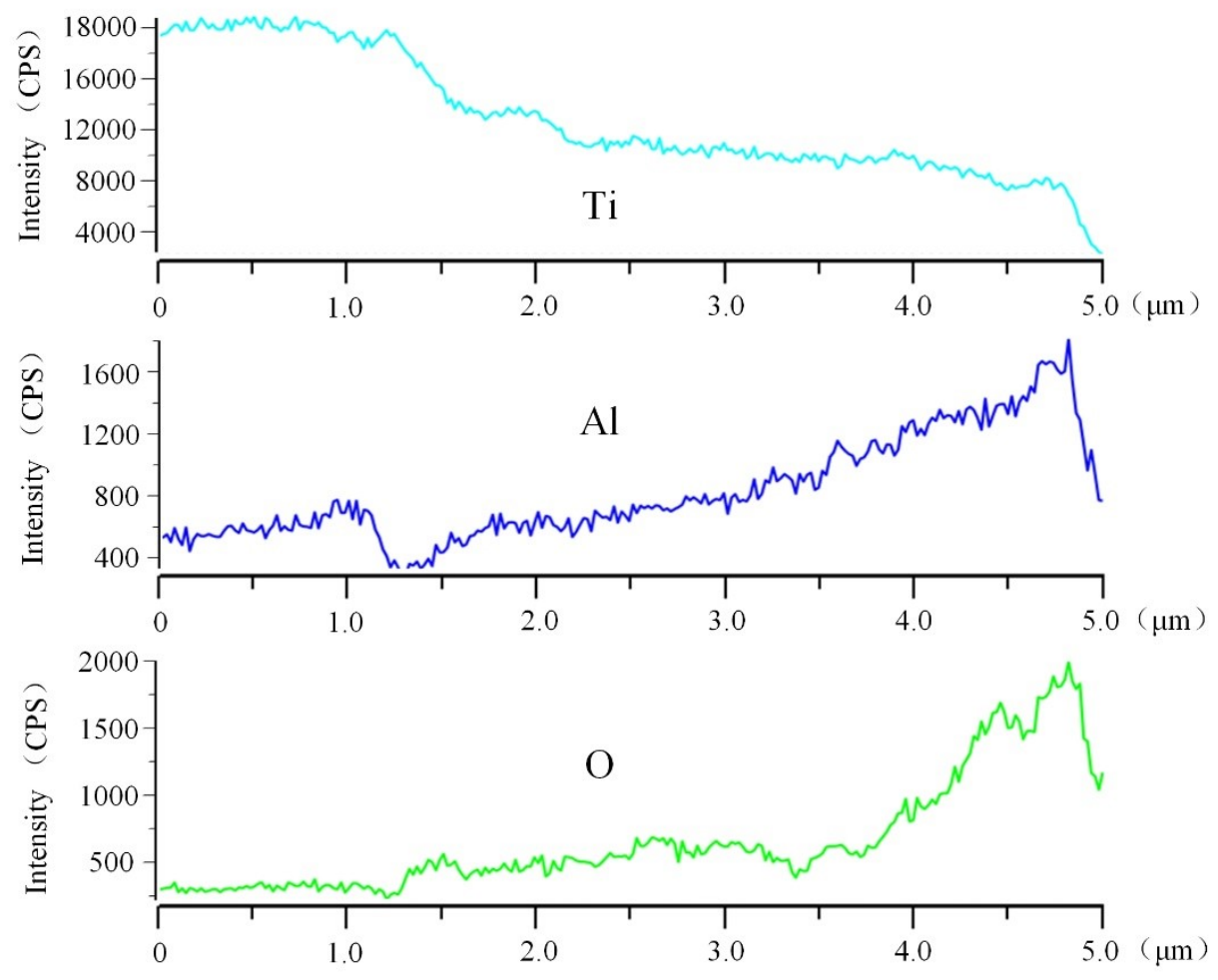

Figure 9. (a-b) FIB cross-section morphologies of the wear scar of Ti6Al4V sample, (c) EDS line scans of the wear scar cross-section.

\subsection{D optical profile}

The 3D surface morphology and wear volume of after 5000-100000 fretting cycles experiments were characterised with optical 3D profiler. Fig. 10 shows the 
wear scar morphology of 316 steel, pure copper and Ti6A14V. Cross-sectional wear depth images were also plotted in order to give more detailed insight into wear scar morphology. Firstly, it can be noticed that Ti6Al4V sample showed the largest wear depth, while pure copper had the smallest wear depth under the same fretting conditions. Secondly, it can be observed that the Ti6Al4V wear scar is characterised by the highest surface roughness, while pure copper sample has the lowest roughness after the same number of fretting cycles.

Further wear behaviour analysis is shown in Fig. 11 for long-duration fretting experiments (5000-100000 cycles). Under the same fretting test conditions, pure copper showed the smallest wear volume and Ti6Al4V showed the poorest wear behaviour.
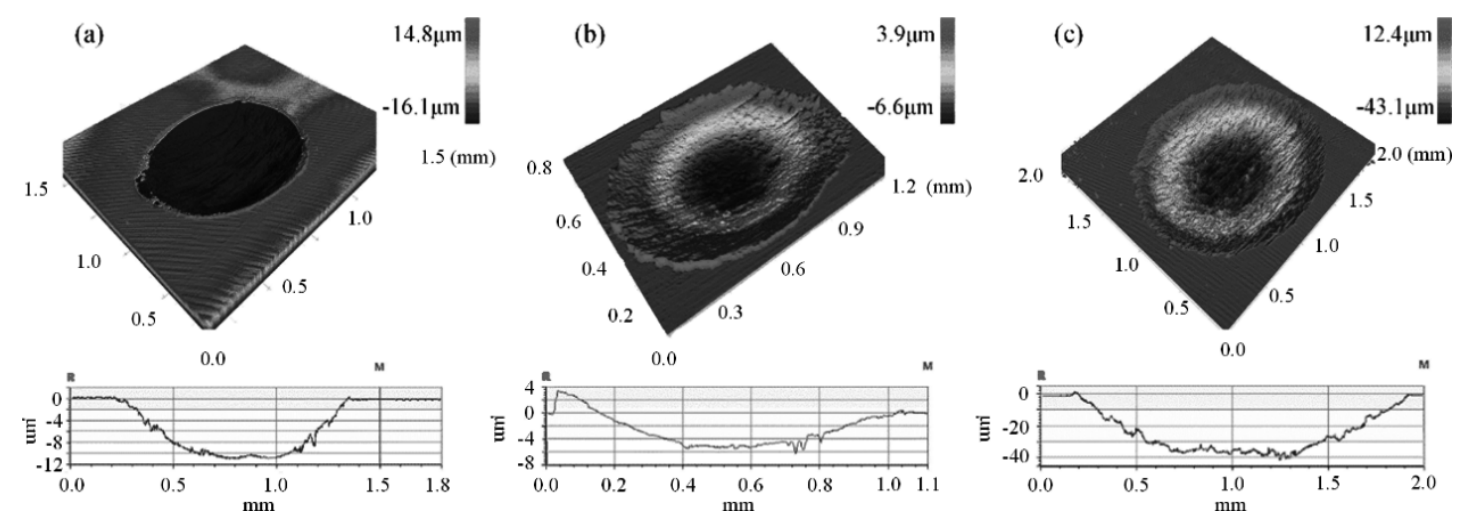

Figure 10. Wear scar morphology after 100000 fretting cycles; (a) 316 stainless steel, (b) pure copper, and (c) Ti6Al4V. 


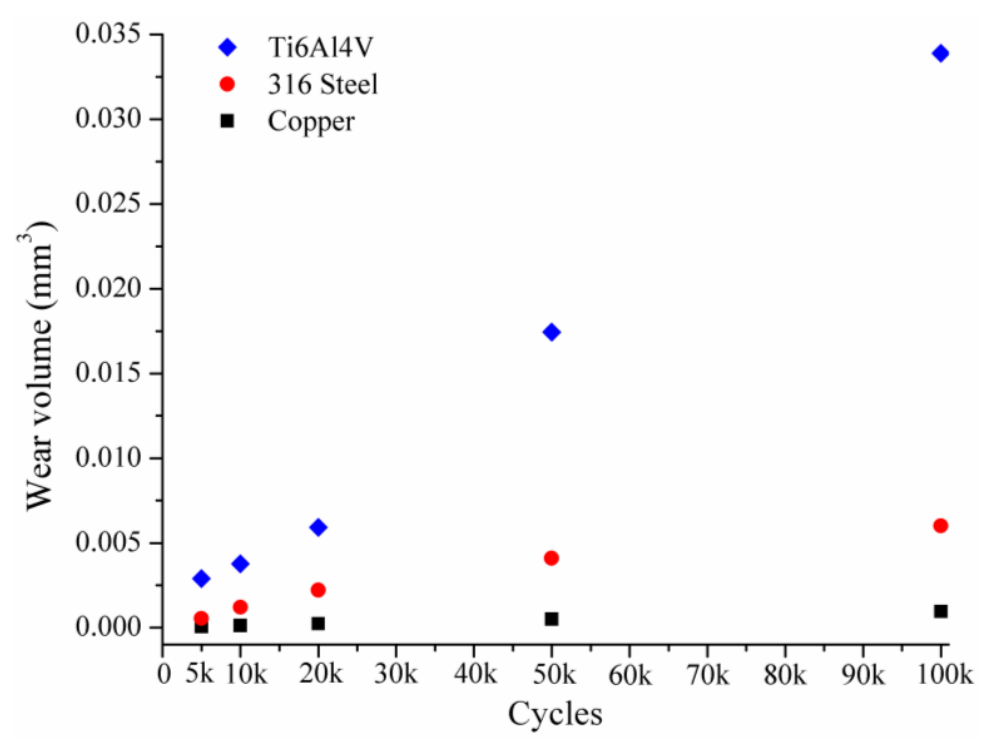

Figure 11. Wear volume of 316 steel, pure copper and Ti6Al4V under 5000-100000 fretting cycles.

\section{Discussion}

Wear of conventional metallic materials involves different complex solid state processes where the dominant process can be elusive. TTS layer structure and properties influence many properties of engineering materials, such as friction, fatigue and abrasive wear properties, etc. [33]. It can be observed from the FIB cross-sections through the fretting scars in Fig. 6-8 that the fretting process leads to TTS layer grain refinement of 316 steel, pure copper and Ti6A14V. During the fretting process, strong dislocation densities are generated by the association of a Hertzian pressure field with stress generated by the presence of an inclusion inside the material [24]. Recrystallization of TTS layer was induced by these dislocations [34]. Zhou et al. [35] investigated the influence of grain size on the tribological properties of steel. They observed that grain refinement of steel produces higher hardness and lower plasticity (i.e. Hall-Petch hardening). When the grain size was not extremely small, smaller 
grain size led to better wear resistance. Researchers also investigated the influence of grain size on the tribological properties of copper [36-40]. A clear correlation was found with wear rate reducing significantly with decreasing grain size in pure copper, which was mainly attributed to the higher hardness of fine-grained copper [39, 40]. Similarly, for Ti6A14V better friction and wear resistance was reported for a modified alloy with refined nanocrystalline surface layer than for untreated Ti6Al4V. After the fretting process, the sample with the refined surface layer exhibited a smaller wear scar and shallower wear depth [41].

The evolution of wear volume is closely related to the durability of materials under fretting wear. Predicting the wear volume is important to estimate the service life of materials under fretting condition. The Archard model is the most widely used wear prediction model at present. In some cases, the prediction shows good agreement with experimental data [42]. In the classical Archard model, the wear volume is given by:

$$
V=k \frac{W S}{H}
$$

where $V$ is wear volume, $W$ is the normal load, $S$ is the sliding distance, $H$ is the hardness of material and $k$ is a wear coefficient which is related to the mechanical performance, structure and interface adhesion performance of material. However, the Archard model does not consider the influence of dynamically changing mechanical properties of the TTS layer on the fretting wear behaviour. In an earlier study, Steiner et al. found that although wear evolution is influenced by many parameters including surface roughness and oxidation that are not considered in Archard model, the 
predictive result with classical Archard wear model was in good agreement with the energy dissipation approach after the running in process at the early stage of friction [43]. This result shows that it is necessary to reflect the changing materials behaviour during the early stage of friction in the Archard wear model.

To consider the influence of mechanical properties of the dynamically evolving TTS layer on the wear volume prediction, the hardness of bulk material $(H)$ was replaced by the hardness of TTS layer $\left(H_{\mathrm{TTS}}\right)$ in an attempt to improve the classical Archard model.

The modified Archard model is described as follows:

$$
V=k \frac{W S}{H_{\mathrm{TTS}}}
$$

The wear coefficient $k$ can be calculated with

$$
k=\frac{V H}{W S}
$$

Where wear volume $V$ and hardness of the bulk materials can be measured with experiments, the sliding distance $S$ can be easily calculated with fretting amplitude and fretting cycles, and the applied normal load is given. We calculated the wear coefficients using equation (4) after tests with 5000, 10000 and 20000 fretting cycles. The proposed approach allows to establish wear coefficient form a short duration test in order to predict wear performance in a long duration experiment with 100000 fretting cycles. The proposed predictive wear model approach is shown schematically in Fig. 12. Firstly, a TTS layer was generated with short duration fretting test. Secondly, the hardness of the TTS layer was measured by nanoindentation. In the 
final step the hardness of the bulk material in Archard model was replaced by the hardness of TTS layer for wear prediction.
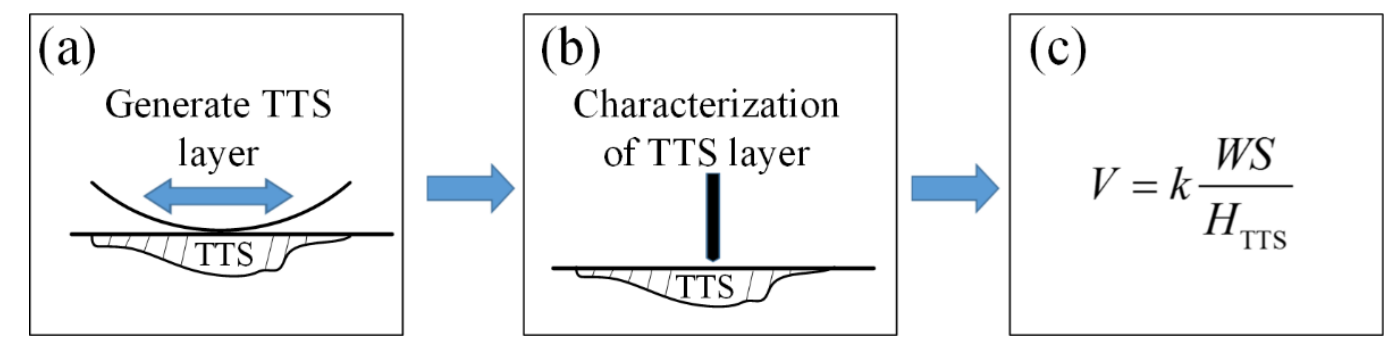

Figure 12. Improved predictive wear model approach. (a) TTS generation, (b)

TTS characterization and (c) modified Archard wear model.

Previous research [23] has noted that the TTS layer can be formed at early stage of fretting, suggesting that the performance of the TTS layer will change little in longer tests. In this study, the hardness after 1000 cycles fretting was used to represent the hardness of the stable TTS layer. Figures 13-15 show how the wear volume of 316 steel, pure copper and Ti6A14V predicted with classical Archard model and modified Archard model compare to the experimental results. The columns represent the wear volume predicted with measured wear volume of 5,000/10,000/20,000 fretting cycles using the Archard model and modified Archard model, respectively. Fig. 13 (a), Fig. 14 (a) and Fig. 15 (a) show the predicted wear volume of 316 steel, pure copper and Ti6A14V after 50,000 cycles fretting, respectively, while Fig. 13 (b), Fig. 14 (b) and Fig. 15 (b) show the results for 100,000 cycles fretting. The experimental wear volume data after 50,000 and 100,000 fretting cycles are plotted as a dotted line for comparison. The difference (\%) between the predicted results and the experimental 
results are listed on the columns.
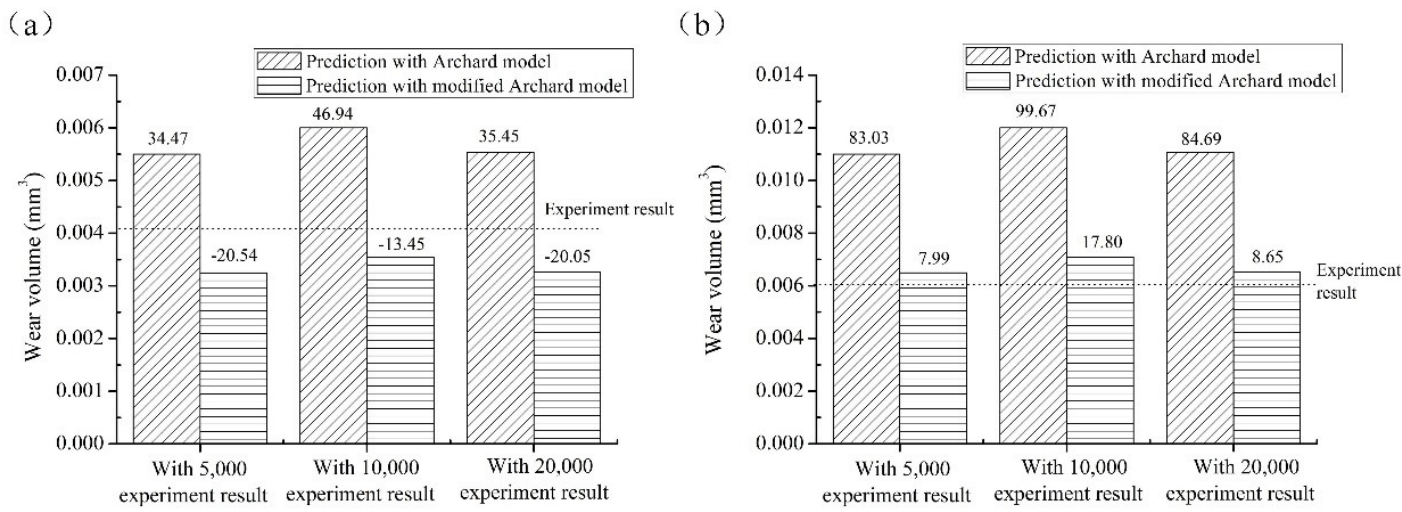

Figure 13. Experimental and predicted wear volume of 316 steel sample with (a)

50,000 fretting cycles and (b) 100,000 fretting cycles. The numbers above the columns represent $\%$ difference between the predicted results and the experimental results.

For 316 stainless steel the wear volume after 50,000 cycles fretting predicted with the classical Archard model deviates from the experimental result by $35 \%, 47 \%$ and $35 \%$, respectively, with the measured wear volume of 5000/10,000/20,000 cycles fretting, while that with modified Archard model are within $21 \%, 13 \%$ and $20 \%$, respectively (Fig. 13a). The wear volume of 100,000 cycles fretting predicted with classical Archard model deviates by $83 \%, 100 \%$ and $85 \%$, respectively, while the wear volume determined with the modified Archard model is within $8 \%, 18 \%$ and $9 \%$, respectively (Fig. 13b). It is clear that the wear volume after 50,000 and 100,000 cycles fretting predicted with modified Archard model are closer to the experimental results with the predicted wear volume of 100,000 cycles fretting being more accurate. 
Since the wear volume of 316 stainless steel increases linearly with the fretting cycles at the initial stage of fretting wear the long-duration wear volume predicted with the wear volume of 5,000/10,000/20,000 fretting cycles is similar.

The formation and evolution of the TTS layer on the material surface is a dynamic process during fretting wear. In the initial stage of the fretting wear, the TTS layer is first formed in the centre of the wear scar, then gradually expand to cover the whole wear scar [23]. The size of wear scar obviously increased with the number of fretting cycles during the early stage of fretting wear. Therefore, although the TTS layer was formed at the centre of the wear scar, the mechanical properties of the wear scar region without TTS layer are closer to the bulk material. After 50,000 cycles fretting, the contact area between the ball and the plane samples is larger than the early stage of fretting, and the enlargement of the wear scar is slower. The distribution of the TTS layer is more uniform after 50,000 fretting cycles so the predicted wear volume of 100,000 fretting cycles with modified Archard model is more accurate than the predicted results of 50,000 fretting cycles.
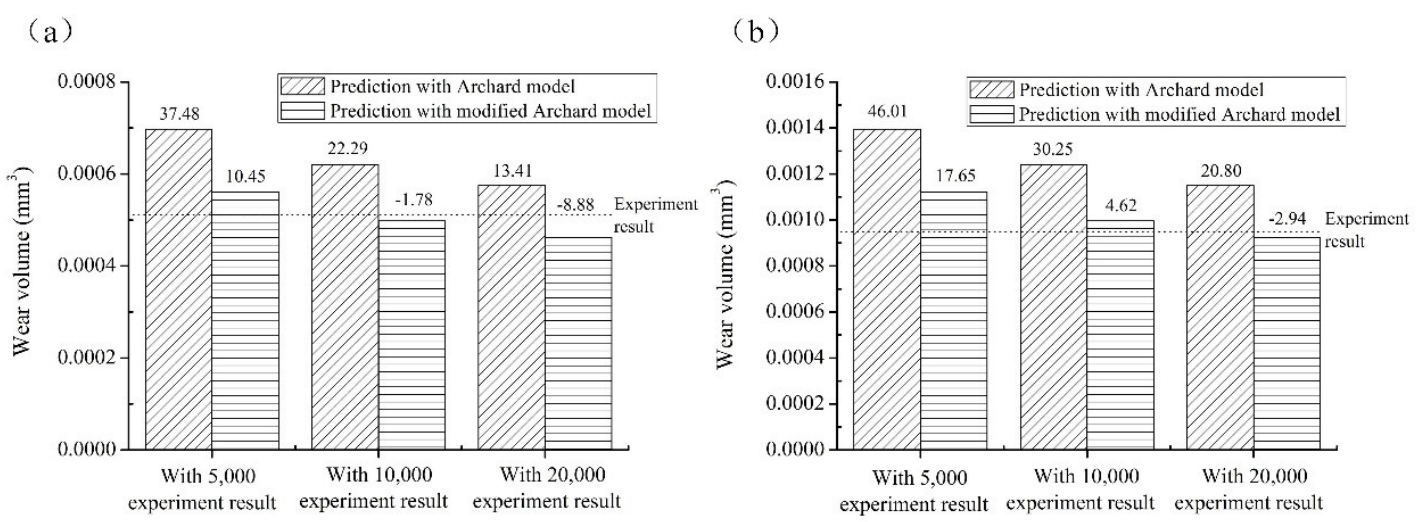

Figure 14. Experimental and predicted wear volume of pure copper sample with (a) 50,000 fretting cycles, and (b) 100,000 fretting cycles. The numbers above the 
columns represent $\%$ difference between the predicted results and the experimental results.

For pure copper, the wear rate was highest during the early stage of fretting then decreased, so the predicted wear volume with 5,000/10,000/20,000 fretting cycles gradually decreases at the same time. The wear volume of 50,000 fretting cycles predicted with the classical Archard model deviated by $37 \%, 22 \%$ and $13 \%$, respectively, while that with modified Archard model was within 10\%, 2\% and 9\%, respectively (Fig, 14a). The predicted wear volume for 100,000 fretting cycles with classical Archard model was within $40 \%, 30 \%$ and $21 \%$, respectively of the experimental result, while the predicted volume with the modified Archard model was within $18 \%, 5 \%$ and $3 \%$, respectively of the experimental result (Fig. 14b). As with 316 steel, using the modified Archard model the predicted wear volumes for both 50,000 and 100,000 fretting cycles are significantly closer to the experimental results than those predicted using the classical Archard model.

Figs. 13 and 14 clearly show that the all the predicted wear volumes with the classical Archard model are higher than the experimental results. For 316 steel and pure copper, a TTS layer with higher hardness was formed on the contact surface during fretting process, which act as protective layer to reduce the fretting wear. Since the predicted wear volume in the Archard model is determined from the hardness of bulk material, it is unable to capture the effect of the higher hardness TTS. In contrast, the predicted wear volume using the TTS hardness in the modified Archard model is 
lower than that with classical Archard model, resulting in better agreement with the experimental results.
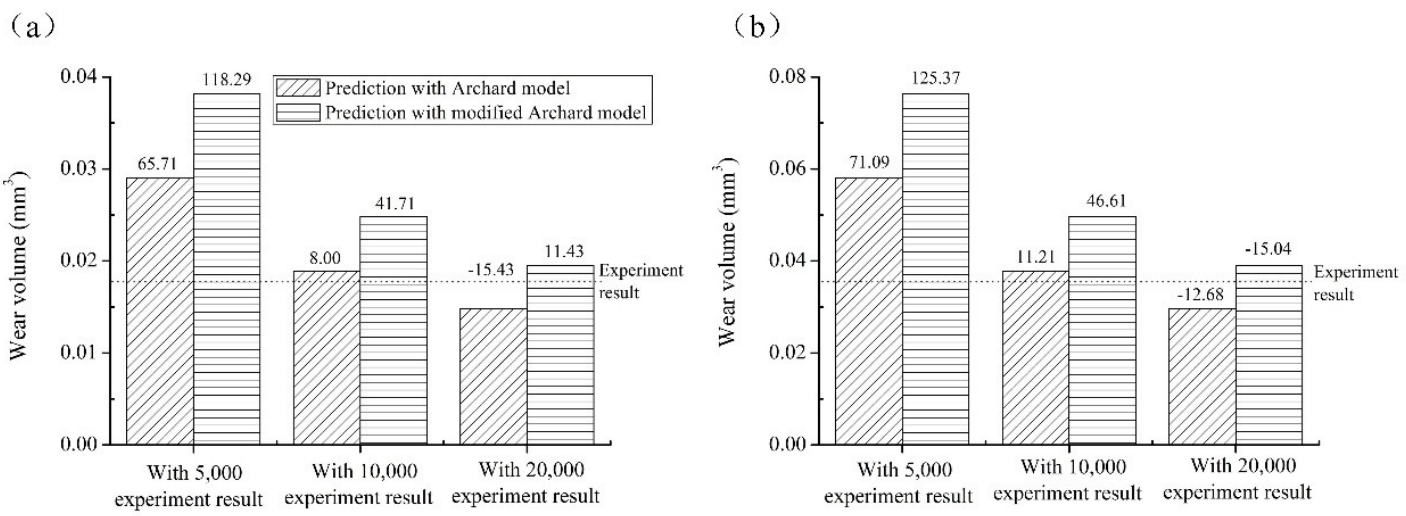

Figure 15. Experimental and predicted wear volume of Ti6Al4V sample with (a) 50,000 fretting cycles, and (b) 100,000 fretting cycles. The numbers above the columns represent $\%$ difference between the predicted results and the experimental results.

The modified model was generally less successful on Ti6Al4V (Fig. 15). The wear volume for 50,000 fretting cycles predicted with classical Archard model deviated by $66 \%, 8 \%$ and $15 \%$, respectively from the experimental value, whilst using the modified Archard model resulted in values deviating by $118 \%, 42 \%$ and $11 \%$, respectively (Fig. 15a). The wear volume after 100,000 fretting cycles predicted by the classical Archard model was $71 \%, 11 \%$ and $13 \%$, respectively away from the actual value, while that predicted with the modified Archard model was within $125 \%$, $47 \%$ and $15 \%$, respectively (Fig. $15 b$ ).

The modified wear prediction model in our study is based on the measured TTS surface hardness using nanoindentation, which can be influenced by the roughness 
and porosity of TTS layer. The hardness was calculated by:

$$
H=\frac{P_{\max }}{A}
$$

where $H$ is hardness, $P_{\max }$ is the peak load and the contact area $A$ can be expressed by

$$
A=F\left(h_{\max }-\varepsilon \frac{P_{\max }}{S}\right)
$$

where $\varepsilon$ is a constant, $S$ is the stiffness [32] and $h_{\max }$ is the maximum depth which is determined experimentally. The contact mechanics analysis assumes that the surface being indented is a plane, without considering the influence of roughness. The magnitude of the surface roughness (e.g. $R_{\mathrm{a}}$ ) and its wavelength relative to the size of the indenter can influence the accuracy of the derived hardness and elastic modulus data. An indentation performed on a roughness valley leads to lower penetration depth $h_{\max }$, (due to higher contact area than expected from a plane surface) and higher calculated hardness assuming a plane surface, while an indentation performed on a roughness peak leads to higher penetration depth and lower calculated hardness [44]. For relatively deep indentations with sharp indenters (as in this study) the influence of roughness is less significant than for shallow indentations with spherical indenters. Previous work has noted that although higher surface roughness leads to higher deviation between each indentation measurement, it has less influence on the average measured hardness with enough measurement repeats [44]. The influence of porosity on surface hardness is different from roughness. The increase of porosity will lead to a sharp decrease in measured hardness, which is dominated by the porosity filling during nanoindentation measurements [45]. The difference in the accuracy of wear 
prediction for Ti6Al4V and for 316 steel or pure copper can be attributed to the added complexity from the influence of microstructure/porosity on the nanoindentation data for the Ti6Al4V TTS layer. The TTS layer with high porosity induced by fretting leads to lower measured hardness by nanoindentation, which results in higher predicted wear volume with modified wear model.

The evolution of the TTS layer is a complex process involving work hardening, oxidation, debris formation and microstructural changes on the wear surface. Previous research has shown that the strength of stainless steel and copper can be easily enhanced through work hardening [46, 47]. The nanoindentation data in this study confirm that the surface hardness of TTS layer of 316 stainless steel and pure copper can be significantly enhanced during fretting. However, the evolution of the TTS layer on Ti6Al4V sample is a more complex process. The grain morphologies in Ti6Al4V include $\alpha$ and $\beta$ phases and $\alpha+\beta$ bi-modal structure. During fretting process, strain-induced $\beta$ to $\alpha$ phase transformation can occur. The mechanical properties of the debris layer, which is formed during fretting process, have been investigated through cross-section indentation [29, 48]. Although the debris layer on the wear scar surface could be significantly work hardened during fretting, leading to the increased hardness, cracks in the debris layer can reduce the debris layer hardness measured with nanoindentation, so that the mean measured hardness in the wear scar is similar or lower than the hardness of bulk material. The nanoindentation mapping results for Ti6Al4V in Fig. 6 (f) show that the centre of the wear scar has lower hardness comparing to bulk material, which can be attributed to the influence of the 
porous/cracked TTS layer, while the edge of the TTS layer has higher hardness. Although the modified model is generally less successful than the classical Archard on Ti6Al4V, the influence of hardness of the TTS is captured in the closer agreement for the longest fretting tests (Fig. 11 shows increased wear rate for 50,000 and 100,000 cycle tests), due to the reduced hardness/work hardening on Ti6A14V. This is consistent with tribological experiments where, for Ti6Al4V, the ploughing component of friction does not decrease with continued wear cycles due to hardening in the same way that it does for 316 steel [49].

\section{Conclusions}

This paper has investigated the evolution of the TTS layer formed on the surface of 316 steel, pure copper and Ti6Al4V during fretting wear against an alumina ball. Surface and cross-sectional morphology of the TTS layer in wear scar was observed with FIB-SEM, and the chemical changes induced by fretting were studied by EDS. Mechanical properties of the TTS layer were measured by nanoindentation, and the wear volume under fretting determined by 3D profilometry. A predictive wear model was proposed considering the dynamic changes of mechanical properties induced by friction in fretting. The main conclusions are:-

(1) For 316 stainless steel and pure copper, the hardness of the TTS layer can be enhanced during fretting wear, reaching a plateau after 200 cycles of fretting. For Ti6Al4V, hardness of the TTS layer was enhanced within 200 cycles fretting, but the hardness of the TTS layer decreased significantly after 1000 cycles.

(2) There were differences in wear scar roughness, with Ti6Al4V having the 
highest wear scar roughness and pure copper the lowest. A dark oxidised layer was found on the TTS layer of 316 steel but this could not be clearly seen on pure copper. A highly oxidised outer layer and less oxidised sublayer could be observed on the TTS layer of Ti6Al4V wear scar. A thick TTS layer with many cracks can be observed on the wear scar of Ti6Al4V. Grain size refinement due to fretting was observed for all three materials.

(3) A modified Archard model was introduced which considers the influence of the TTS layer on the material wear behaviour. The wear volume of long duration fretting tests was predicted with both classical Archard model and modified Archard model. The results show that modified Archard model can predict the wear volume of 316 steel and pure copper more accurately than the classical Archard model. The modified model was less successful in predicting wear volume on Ti6Al4V where there is added complexity from changing microstructure, oxidation, porosity and cracking.

\section{References}

[1] E. Rabinowicz, Friction and wear of materials, 2th ed. New York: John Wiley \& Sons 1995.

[2] O. Vingsbo, S. Söderberg, On fretting maps, Wear 126 (1988) 131-147.

[3] P. L. Hurricks, The mechanism of fretting — a review, Wear 15 (1970) 389-409.

[4] R. B. Waterhouse, Fretting wear, Wear 100 (1984) 107-118.

[5] D. Aldham, J. Warburton, R. E. Pendlebury, The unlubricated fretting wear of mild steel in air, Wear 106 (1985) 177-201.

[6] I. M. Feng, B. G. Rightmire, An experimental study of fretting, Proc. Inst. Mech. Eng. 170 (1956) 1055-1064.

[7] C. Paulin, S. Fouvry, S. Deyber, Wear kinetics of Ti-6Al-4V under constant and variable fretting sliding conditions, Wear 259 (2005) 292-299. 
[8] J. F. Archard, Contact and rubbing of flat surfaces, J. Appl. Phys. 24 (1953) 981-988.

[9] J. F. Archard, W. Hirst, The wear of metals under unlubricated conditions, P. Roy. Soc. A-Math. Phy. 236 (1956) 397-410.

[10] S. Fouvry, P. Duo, P. Perruchaut, A quantitative approach of Ti-6Al-4V fretting damage: friction, wear and crack nucleation, Wear 257, (2004) 916-929.

[11] A. Leyland, A. Matthews, On the significance of the H/E ratio in wear control: a nanocomposite coating approach to optimised tribological behaviour, Wear 246 (2000) 1-11.

[12] J. Musil, F. Kunc, H. Zeman, H. Polakova, Relationships between hardness, Young's modulus and elastic recovery in hard nanocomposite coatings, Surf. Coat. Technol. 154 (2002) 304-313.

[13] T. W. Liskiewicz, B. D. Beake, N. Schwarzer, M. I. Davies, Short note on improved integration of mechanical testing in predictive wear models, Surf. Coat. Technol. 237 (2013) 212-218.

[14] M. Godet, The third-body approach: a mechanical view of wear, Wear 100 (1984) 437-452.

[15] K. Hiratsuka, K. Muramoto, Role of wear particles in severe-mild wear transition, Wear 259 (2005) 467-476.

[16] J. F. Panzarino, Z. Pan, T. J. Rupert, Plasticity-induced restructuring of a nanocrystalline grain boundary network, Acta. Mater. 120 (2016) 1-13.

[17] R. J. Asaro, S. Suresh, Mechanistic models for the activation volume and rate sensitivity in metals with nanocrystalline grains and nano-scale twins, Acta. Mater. 53 (2005) 3369-3382.

[18] P. Gu, B. K. Kad, M. Dao, A modified model for deformation via partial dislocations and stacking faults at the nanoscale, Scripta Mater. 62 (2010) 361-364.

[19] P. Gu, M. Dao, R. J. Asaro, S. Suresh, A unified mechanistic model for size-dependent deformation in nanocrystalline and nanotwinned metals, Acta. Mater. 59 (2011) 6861-6868.

[20] H. A. Padilla II, B. L. Boyce, C. C. Battaile, S. V. Prasad, Frictional performance and near-surface evolution of nanocrystalline Ni-Fe as governed by contact stress and sliding velocity, Wear 297 (2013) 860-871.

[21] N. Argibay, T. A. Furnish, B. L. Boyce, B. G. Clark, M. Chandross, Stress-dependent grain size evolution of nanocrystalline Ni-W and its impact on friction behavior. Scripta Mater. 123 (2016) 26-29.

[22] P. Blanchard, C. Colombie, V. Pellerin, S. Fayeulle, L. Vincent, Material effects in fretting wear: application to iron, titanium, and aluminum alloys, Metall. Trans. A 22 (1991) 1535-1544.

[23] Z. R. Zhou, E. Sauger, J. J. Liu, L. Vincent, Nucleation and early growth of tribologically transformed structure (TTS) induced by fretting, Wear 212 (1997) 50-58.

[24] E. Sauger, S. Fouvry, L. Ponsonnet, P. Kapsa, J. M. Martin, L. Vincent, Tribologically transformed structure in fretting, Wear 245 (2000) 39-52.

[25] T. Liskiewicz, K. Kubiak, T. Comyn, Nanoindentation mapping of fretting-induced surface layers, Tribol. Int. 108 (2017) 186-193.

[26] F. Liu, W. J. Dan, W. G. Zhang, Strain hardening model of twinning induced plasticity steel at different temperatures, Mater. Des. 65 (2015) 737-742.

[27] R. K. Gupta, V. A. Kumar, C. Mathew, G. S. Rao, Strain hardening of titanium alloy Ti6Al4V sheets with prior heat treatment and cold working, Mater. Sci. Eng. A 662 (2016) 537-550.

[28] X. Peng, D. Zhu, Z. Hu, W. Yi, H. Liu, M. Wang, Stacking fault energy and tensile deformation behavior of high-carbon twinning-induced plasticity steels: effect of $\mathrm{Cu}$ addition, Mater. Des. 45 (2013) 518-523. 
[29] N. M. Everitt, J. Ding, G. Bandak, P. H. Shipway, S. B. Leen, E. J. Williams, Characterisation of fretting-induced wear debris for Ti-6Al-4 V, Wear 267 (2009) 283-291.

[30] B. D. Beake, T. W. Liskiewicz, V. M. Vishnyakov, M. I. Davies, Development of DLC coating architectures for demanding functional surface applications through nano- and micro-mechanical testing, Surf. Coat. Tech. 284 (2015) 334-43.

[31] G. M. Pharr, W. C. Oliver, F. R. Brotzen, On the generality of the relationship among contact stiffness, contact area, and elastic-modulus during indentation, J. Mat. Res. 7 (1992) 613-7.

[32] W. C. Oliver, G. M. Pharr, An improved technique for determining hardness and elastic modulus using load and displacement sensing indentation experiments. J Mater. Res. 7(1992), 1564-1583.

[33] G. Li, J. Chen, D. Guan, Friction and wear behaviors of nanocrystalline surface layer of medium carbon steel, Tribol. Int. 43 (2010) 2216-2221.

[34] R. Österlund, O. Vingsbo, L. Vincent, P. Guiraldencq, Butterflies in fatigued ball-bearings: formation mechanisms and structure, Scand. J. Metal. 11 (1982) 23-32.

[35] L. Zhou, G. Liu, Z. Han, K. Lu, Grain size effect on wear resistance of a nanostructured AISI52100 steel, Scripta Mater. 58 (2008) 445-448.

[36] Y. S. Zhang, Z. Han, K. Wang, K. Lu, Friction and wear behaviors of nanocrystalline surface layer of pure copper, Wear 260 (2006) 942-948.

[37] Y. S. Zhang, H. Z. Niu, L. C. Zhang, X. F. Bai, X. M. Zhang, P. X. Zhang, Grain coarsening behavior in a nanocrystalline copper subjected to sliding friction, Mater. Lett. 123 (2014) 261-264.

[38] Y. S. Zhang, Z. Han, K. Lu, Fretting wear behavior of nanocrystalline surface layer of copper under dry condition, Wear 265 (2008) 396-401.

[39] B. Yao, Z. Han, K. Lu, Correlation between wear resistance and subsurface recrystallization structure in copper, Wear 294 (2012) 438-445.

[40] W. L. Li, N. R. Tao, Z. Han, K. Lu, Comparisons of dry sliding tribological behaviors between coarse-grained and nanocrystalline copper, Wear 274 (2012) 306-312.

[41] A. Amanov, I. S. Cho, D. E. Kim, Y. S. Pyun, Fretting wear and friction reduction of CP titanium and Ti-6Al-4V alloy by ultrasonic nanocrystalline surface modification, Sur. Coat. Tech. 207 (2012) 135-142.

[42] V. Hegadekatte, S. Kurzenhäuser, N. Huber, O. Kraft, A predictive modeling scheme for wear in tribometers, Tribol. Int. 41 (2008) 1020-1031.

[43] L. Steiner, V. Bouvier, U. May, V. Hegadekatte, N. Huber, Modelling of unlubricated oscillating sliding wear of DLC-coatings considering surface topography, oxidation and graphitization, Wear 268 (2010) 1184-1194.

[44] K. D. Bouzakis, N. Michailidis, S. Hadjiyiannis, G. Skordaris, G. Erkens, The effect of specimen roughness and indenter tip geometry on the determination accuracy of thin hard coatings stressstrain laws by nanoindentation, Mater. Charact.49(2002), 149-156.

[45] J. Luo, R. Stevens, Porosity-dependence of elastic moduli and hardness of 3Y-TZP ceramics. Ceram. Int. 25(1999), 281-286.

[46] J. D. Lemm, A. R. Warmuth, S. R. Pearson, P. H. Shipway, The influence of surface hardness on the fretting wear of steel pairs - Its role in debris retention in the contact, Tribol. Inter. 81 (2015) 258-66.

[47] Y. Estrin, H. Mecking, A unified phenomenological description of work hardening and creep based on one-parameter models, Acta Metall. 32 (1984) 57-70. 
[48] D. R. Swalla, R. W. Neu, D. L. McDowell, Microstructural characterization of Ti6Al4V subjected to fretting, ASME/STLE 2004 International Joint Tribology Conference. American Society of Mechanical Engineers, 2004.

[49] B.D. Beake, T.W. Liskiewicz, Comparison of nano-fretting and nano-scratch tests on biomedical materials, Tribol. Int. 63 (2013) 123-131. 